\title{
High-Pressure Capturing Wing Configurations
}

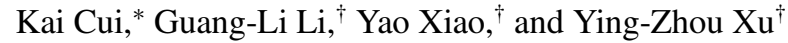 \\ Chinese Academy of Sciences, 100190 Beijing, People's Republic of China
}

DOI: $\underline{10.2514 / 1 . J 055395}$

\begin{abstract}
This paper proposes a family of high-pressure capturing wing configurations that aim to improve the aerodynamic performance of hypersonic vehicles with large volumes. The predominant visual feature of such configurations is a thin wing called a high-pressure capturing wing attached to the top of an upwarp airframe. When flying in the hypersonic regime, high-pressure airflow compressed by the upper surface of the vehicle acts on the high-pressure capturing wing and significantly augments lift on the vehicle with only a small increase in drag, producing a correspondingly high increase in its lift-to-drag ratio. A series of numerical validations were carried out on the basis of both inviscid and viscous computational models in which ideal cones with different cone angles and combined conewaverider bodies with different volumes were used as airframes. The results clearly demonstrate that a configuration using a high-pressure capturing wing has a significantly higher lift (with a correspondingly high value of lift-to-drag ratio) than one without a high-pressure capturing wing, especially for vehicles with large volumes. This paper contains a preliminary, results-based report of the conditions under which high-pressure capturing wing configurations were tested.
\end{abstract}

\section{Nomenclature}

$C_{A} \quad=$ axial-force coefficient

$C_{d}=$ drag coefficient

$C_{l} \quad=$ lift coefficient

$C_{N} \quad=$ normal-force coefficient

$D \quad=$ drag

$d \quad=$ diameter

$H \quad=$ flight altitude

$I_{\mathrm{sp}} \quad=$ specific impulse

$L=$ lift, length

$M a=$ Mach number

$P \quad=$ pressure

$R \quad=$ radius

Re $\quad=$ Reynolds number

$S_{p} \quad=\quad$ normal projection area

$S=$ shock wave, integral domain

$V \quad=$ volume

$V_{c} \quad=$ cruising speed

$W \quad=$ gross weight, width

$\alpha=$ angle of attack

$\beta \quad=$ shock-wave angle

$\gamma \quad=$ ratio of specific heats

$\Delta n=$ nondimensional height of the first layer near the wall

$\eta \quad=\quad$ ratio of average pressure on different surfaces

$\theta \quad=$ wedge angle, half-cone angle

$\xi \quad=$ volumetric efficiency

$\rho \quad=$ density

\section{Subscripts}

$B \quad=$ body

$H=$ high-pressure capturing wing

$\mathrm{HCWL}=$ lower surface of the high-pressure capturing wing

$\mathrm{HCWU}=$ upper surface of the high-pressure capturing wing

Presented as Paper 2015-3388 at the 15th AIAA Aviation Technology, Integration, and Operations Conference, Dallas, TX, 22-26 June 2015; received 29 May 2016; revision received 16 November 2016; accepted for publication 14 December 2016; published online 9 March 2017. Copyright (C) 2016 by the American Institute of Aeronautics and Astronautics, Inc. All rights reserved. All requests for copying and permission to reprint should be submitted to CCC at www.copyright.com; employ the ISSN 0001-1452 (print) or 1533-385X (online) to initiate your request. See also AIAA Rights and Permissions www.aiaa.org/randp.

*Associate Professor, LHD of Institute of Mechanics, Haidian; kcui@ imech.ac.cn; also Professor, School of Engineering Science, University of Chinese Academy of Sciences, Beijing 100049, People's Republic of China.

${ }^{\dagger}$ Graduate Student, LHD of Institute of Mechanics, Haidian.

\section{Introduction}

$\mathbf{H}$ YPERSONIC flight vehicles, which are aircraft with flight Mach numbers greater than 5, have been of great interest in the past few decades. Among these, the so-called hypersonic airbreathers are considered a research hotspot. Recent interest in these vehicles has grown explosively, and various types of innovative vehicles, such as the X-51A, which is a combined U.S. Air Force and Defense Advanced Research Projects Agency program [1], the Boeing Flexible Aerospace System Solution for Tomorrow [2] $]$, and the Boeing Hypersonic Space and Global Transportation System [3] have been proposed and studied. Despite entering the age of hypersonic flight with the success of the X-43A [4] and the X-51A [1] , scientists and engineers are conscious about the many unsolved problems that limit the practical application of air-breathers.

In contrast, the development of rocket engines has reached maturity. They had been widely used as propulsive units in the boosting phase for various spacecrafts such as space shuttles. Theoretically, it is possible to use a rocket engine as a substitute for the scramjet in a hypersonic cruise vehicle (HCV). To discuss the feasibility of rocket-powered HCVs, Fan [5] established a coupling analysis model to assess flight performance. In his study, the optimal cruise speed was attained by analyzing flight performance measured by the ratio of initial boost mass to generalized payload. In addition, the performance of HCVs based on rockets and air-breathing scramjets was studied and compared to that of a minimum-energy ballistic trajectory under a certain flight distance. Results of the theoretical analysis indicate that rocket-based HCVs flying at the optimal speed in a hypersonic regime is a very competitive choice.

Rocket engines are more powerful than present-day air-breathing scramjets, and so they can produce sufficient thrust (from several kilonewtons to several meganewtons) in almost all flying conditions. However, the main shortcoming of a rocket is that it must carry enough oxidant for the entire journey. The low specific impulse of rocket engines make them impractical for cruise vehicle propulsion unless the cruise range is very short. For relatively long range, the required vehicle propellant fraction would be prohibitively large. This inevitably leads to the enlargement of its volume, and a corresponding increase in net weight. Consequently, there are several special requirements for a rocket-based HCV over a hypersonic airbreather. First, the vehicle must provide the extra volume to contain the oxidant in addition to fuels and other payloads. Next, the vehicle must produce a lift large enough to overcome its weight and to maintain a cruise state. Finally, the performance of a rocket-based vehicle can be assured only if the vehicle has a high lift-to-drag ratio $(L / D)$ configuration, according to the analysis in [5].

A high $L / D$ value is a primary goal pursued by aerodynamic configuration designers because it is directly proportional to the flight 
range, either for a cruise vehicle or for a hypersonic glider [6]. However, it is difficult to obtain a high $L / D$ for a generic configuration due to the presence of strong shock-wave drag and massive viscosity under hypersonic flight conditions. Among the existing configurations, the waverider has been deemed the most promising because the containment of flow beneath the vehicle results in a high pressure being exerted on the lower surface. Because of this advantage, the concept has received a lot of attention over the years after its inception by Nonweiler in 1959 [7]. In the wake of the arrival of a family of viscous optimized waveriders [8], a lot of literature about their design methodologies [9-12], performance evaluations [13-19], and proposed applications [20-25] was published.

Despite the fact that waverider configurations have been investigated in the past few decades, they have not yet been adopted for practical flight. In fact, the current usage of a waverider is mostly in the precompression surface of inlets, typically of an X-51A scramjet demonstration vehicle, rather than a high $L / D$ vehicle. In general, a pure waverider with high $L / D$ is relatively thin, and so it can hardly provide enough volume for fuel and payloads [26], especially for a rocket-based HCV. A solution to this problem is to enlarge the size of the vehicle $[21,27]$, but this also results in a drastic increase in aerodynamic drag as well as vehicle gross weight, making it difficult to simultaneously meet the thrust-to-drag and lift-toweight requirements. A more practical method of adding volume to a pure waverider is to morph the upper surface (i.e., to replace the freestream surface by an upwarp) $[15,28,29]$. However, this canopy actually forms a compression surface on the upper part of the vehicle, which leads to an increase of both the aerodynamic drag and the negative lift, causing an overall reduction in $L / D$. This problem is the motivation behind this study.

Many studies have been made concerning the favorable lift interference in supersonic and hypersonic flow [30-32]. Results reported in $[30,31]$ indicate that the half-ring wing and parasol wing could obtain favorable lift interference produced by the body in supersonic flow. The investigation of [32] indicates that an appropriate sweep forward of wings could partly capture the highpressure airflow generated by the body. Inspired by the preceding results, this paper proposes a novel configuration called highpressure capturing wing $(\mathrm{HCW})$ that focuses on effectively using the high-pressure airflow compressed by the upper surface. The basic philosophy of the HCW configuration is to append a thin wing at an appropriate position upon the body. In hypersonic flight, the highpressure airflow compressed by the upper surface acts on the HCW and provides the vehicle with extra lift. Furthermore, it results in a considerable increment in the value of $L / D$.

The main purpose of this paper is to test the validity of the HCW configurations at a conceptual level. The rest of this paper is organized as follows. In Sec. II, the principle of the HCW is elaborated upon based on the shock-expansion theory of inviscid, compressible flow [33]. In Sec. III, a preliminary relationship between volume and aerodynamic performance is explored by taking a family of circular cones as vehicle bodies on the basis of twodimensional, inviscid simulations. In Sec. IV, the aerodynamic performance of three waverider-HCW configurations with different volumes is predicted for the purpose of future validation. Finally, Sec. $\underline{V}$ draws several conclusions that point the way for future work.

\section{Design Principle of the High-Pressure Capturing Wing Configuration}

Figure 1 shows a two-dimensional illustration that illustrates the principle of lift enhancement in an HCW configuration. The most obvious difference from existing hypersonic aircraft is the thin wing (i.e., the $\mathrm{HCW}$ ) that is appended to the body. The body is the main part of the vehicle and can be designed as one of several upwarps to provide enough volume. Typically, the upper surface of the body is wedge- or cone-shaped. It is clear that the volume of the vehicle increases with the increase of the wedge angle or half-cone angle $\theta$. Note that only the upper surface of the body is shown in Fig. 1 because the HCW only relates to this surface. For the convenience of

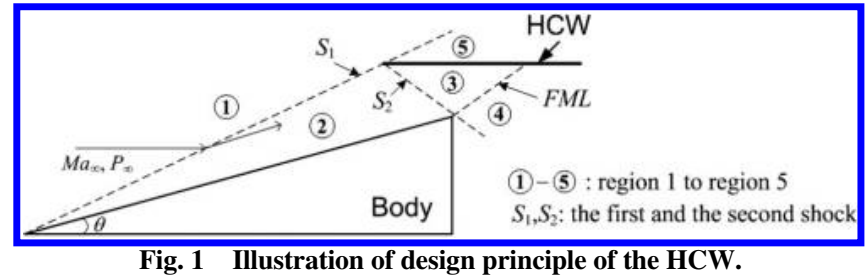

the subsequent analysis, an idealized sharp cone shape is used, and the thickness of the HCW is assumed to be zero.

As shown in Fig. 1, the flowfield around the body and the HCW is not complex. The high-speed freestream airflow with a Mach number $M a_{\infty}$ is fist compressed by the body. The first oblique shock wave appears, denoted by $S_{1}$. At the same time, the direction of the compressed airflow turns upward. If the HCW is parallel to the direction of the freestream, as shown here, a second oblique shock wave denoted by $S_{2}$ is created when the downstream airflow acts on the HCW. Along with the airflow flowing downstream, an expansion region that starts from the forward Mach line (FML, shown in Fig. 1) appears when the airflow passes over the edge of the body.

To facilitate the analysis, the flowfield in Fig. 1 is divided into five regions, labeled from 1 to 5 in accordance with the positions of the shock and the expansion waves. It is obvious that the air pressure in region 1 is the freestream pressure, and the pressure in region 2 is higher than that in region 1 because the airflow is compressed by the body. When the airflow arrives in region 3 , the pressure continues to increase because the HCW compresses the airflow again. As the airflow leaves region 3 and enters region 4 , the pressure gradually decreases due to the existence of the expansion fan. The pressure in region 5 is approximately equal to the freestream pressure because the $\mathrm{HCW}$ is parallel to the direction of the freestream flow. On the basis of the preceding analysis, the pressure on the lower surface of the HCW must be much higher than the pressure on its upper surface. The HCW, benefiting from the pressure difference between its lower and the upper surfaces, gets considerable lift augmentation.

The relative placement of the HCW with respect to the body is the main factor that influences the performance of an $\mathrm{HCW}$ configuration. Figure 2 shows three typical cases. Figure $\underline{2 a}$ shows that the high pressure in region 3 touches the body because the distance between the HCW and the body is very short. Thus, it will lead to an increase of the negative lift of the body. However, an HCW will prove expensive when this distance is too great because it cannot borrow the high pressure compressed by the body, as shown in Fig. 2b. Inspired by the design principle of waveriders, an intuitive design rule is to place the leading edge of the HCW on the first shock. The second shock $S_{2}$ should be allowed to just bypass the peak position of the body's trailing edge by adjusting the vertical distance between the HCW and the body, as illustrated in Fig. 2c. It should be noted that this rule has been applied in all cases of this paper.

The pressure difference between the lower and the upper surfaces of the HCW dictates the lift increment for the configuration. For twodimensional wedge bodies, the pressure on the lower surface can be obtained by solving the oblique shock equations, whereas the pressure on the upper surface can be calculated on the basis of the oblique shock equations as well as the Prandtl-Meyer expansion wave equations. Therefore, the pressure ratio of the lower (region 3 in Fig. 1) and the upper (region 5 in Fig. 1) surfaces can be directly calculated according to the shock-expansion theory [33] of inviscid, compressible flow. Curves of this ratio varying with freestream Mach number and wedge angle are plotted in Fig. 3 , where, for air at standard conditions, $\gamma=1.4$. Note that the curve in Fig. $3 \mathrm{a}$ is plotted at the given freestream Mach number 6, whereas the curve in Fig. 3b is plotted at the given wedge angle of $12 \mathrm{deg}$. It is clear that the pressure ratio is directly proportional to both the freestream Mach number and the wedge angle. This indicates that the lift of the configuration might increase drastically.

If the body is a cone, a computational fluid dynamics (CFD) analysis can show the distribution of the entire flowfield. The twodimensional, axisymmetric Euler equations are taken as governing equations for this condition. Structured grids are used to discretize the 


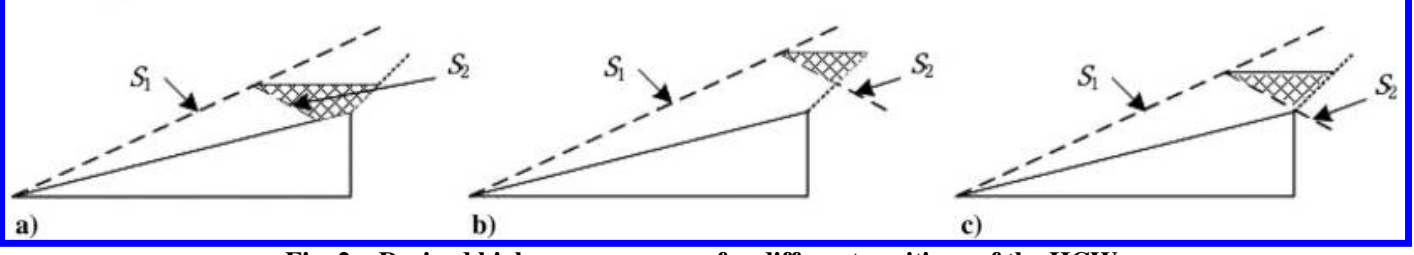

Fig. 2 Derived high-pressure zones for different positions of the HCW.

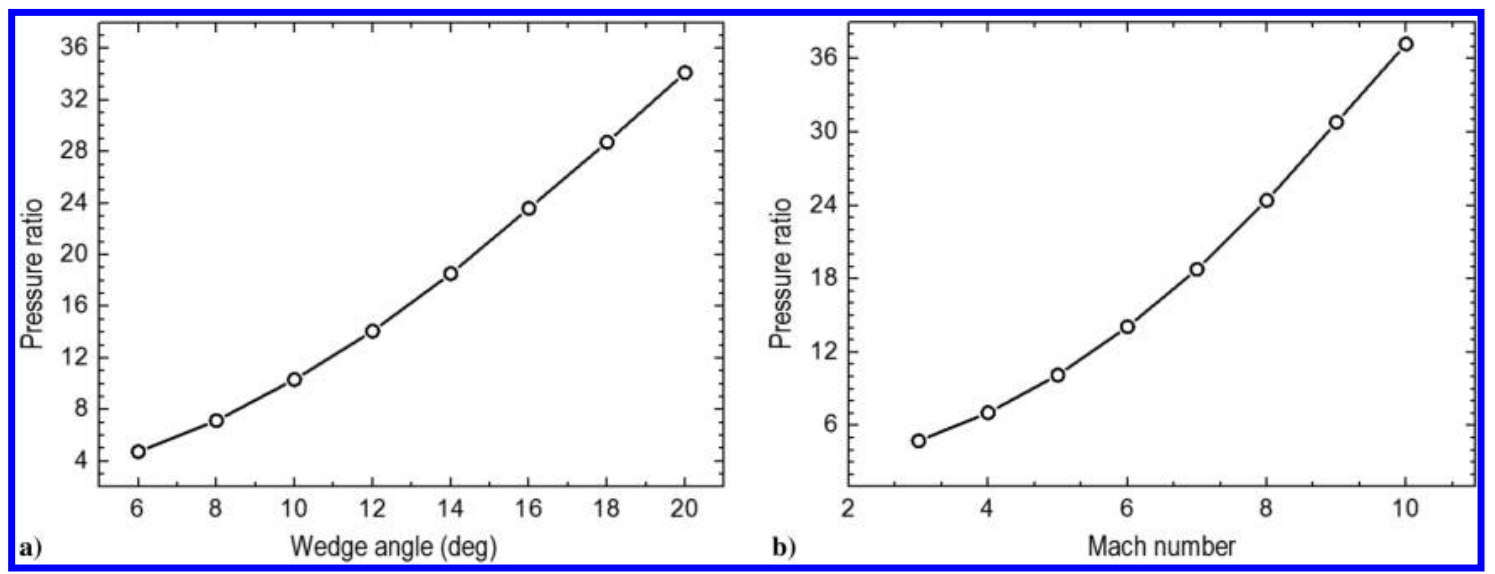

Fig. 3 Variations of the pressure ratio with wedge angle and Mach number for wedge bodies.

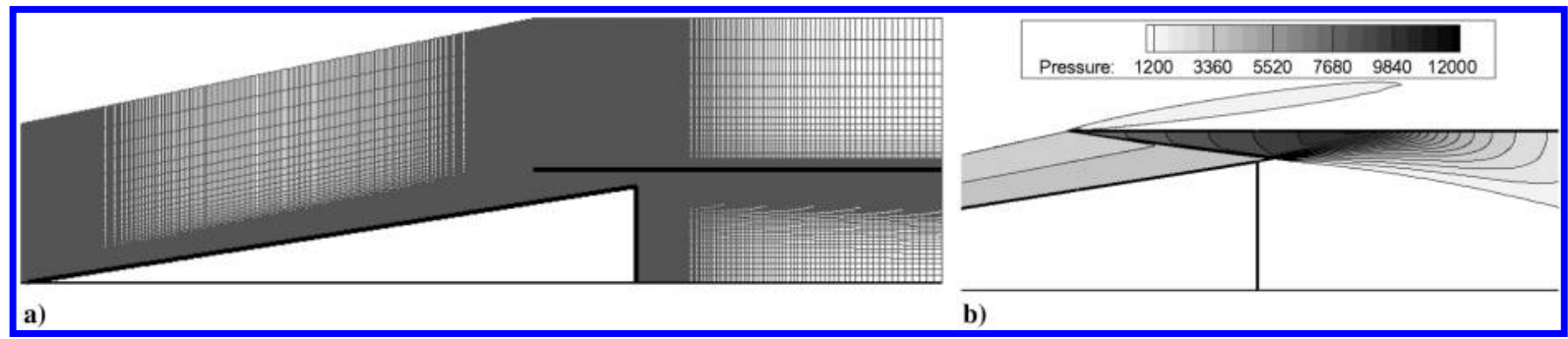

Fig. 4 Grid structure and pressure contour for two-dimensional HCW configuration with cone body at $M a=7, \theta=9 \mathrm{deg}$.

flowfield. The grid structure is shown in Fig. 4a, and a typical computed pressure contour around the $\mathrm{HC} \overline{\mathrm{W}}$ (at $M a=7$, $\theta=9 \mathrm{deg}$ ) is shown in Fig. $4 \mathrm{~b}$. We can clearly distinguish the first shock, the second shock, and the expansion fan from this figure. In addition, the pressure difference between the lower and the upper surface of the HCW can be also clearly observed.

Curves of the ratio of the pressure integration varying with the Mach number and the half-cone angle can be plotted on the basis of a series CFD analysis. However, because the pressure distribution is not uniform for a conical flowfield, an average pressure ratio $\eta$ is defined as follows for such cases:

$$
\eta=\frac{\int_{0}^{L} P_{\mathrm{HCWL}} \mathrm{d} L}{\int_{0}^{L} P_{\mathrm{HCWU}} \mathrm{d} L}
$$

where $L$ is the length of the $\mathrm{HCW}$, and $P_{\mathrm{HCWL}}$ and $P_{\mathrm{HCWU}}$ are the pressure distributions on the lower and the upper surfaces of the $\mathrm{HCW}$, respectively. By imitating the analysis procedure for wedge bodies, curves of $\eta$ varying with Mach number and half-cone angle are plotted in Fig. 5. Note that the curve in Fig. 5a is plotted at the given freestream Mach number 7, whereas the curve in Fig. 5b is plotted at given wedge angle $9 \mathrm{deg}$. The curves in this figure make manifest that there are also considerable values of the pressure ratio when the body is a cone. In addition, the pressure ratio is also directly proportional to both the freestream Mach number and the halfcone angle.

\section{Evaluation of Cone Body with High-Pressure Capturing Wing Configurations}

The preceding analysis and results demonstrate that the pressure difference between the lower and the upper surfaces of the HCW is proportional to both the Mach number and the wedge/cone angle. This suggests that the aerodynamic lift produced by the HCW should increase with the flight speed or the volume. A series of test cases are carried out to make a preliminary exploration into the relationship between the aerodynamic performance and the Mach number as well as the volume. All the cases in this section have used cones as bodies. For simplicity and because aerodynamic lift is the main concern, the thickness of the HCWs and the viscous effects are not considered for the cases within this section.

\section{A. Aerodynamic Forces Calculation Method}

A simplified method has been used for the calculation of aerodynamic forces. According to the design philosophy of HCW configurations, the relationship between the body and the HCW is semicoupled. In other words, although the effectiveness of an HCW relies on the body, the airflow around the HCW would not affect the body. Therefore, the aerodynamic forces can be calculated separately. Moreover, the cone body only generates aerodynamic drag, whereas the HCW produces both lift and drag if the flight angle of attack is set to zero.

A typical configuration including a circular cone body and a halfbarrel HCW is shown in Fig. 6. For such a configuration, the drag of the cone body can be directly evaluated by using a two-dimensional, 


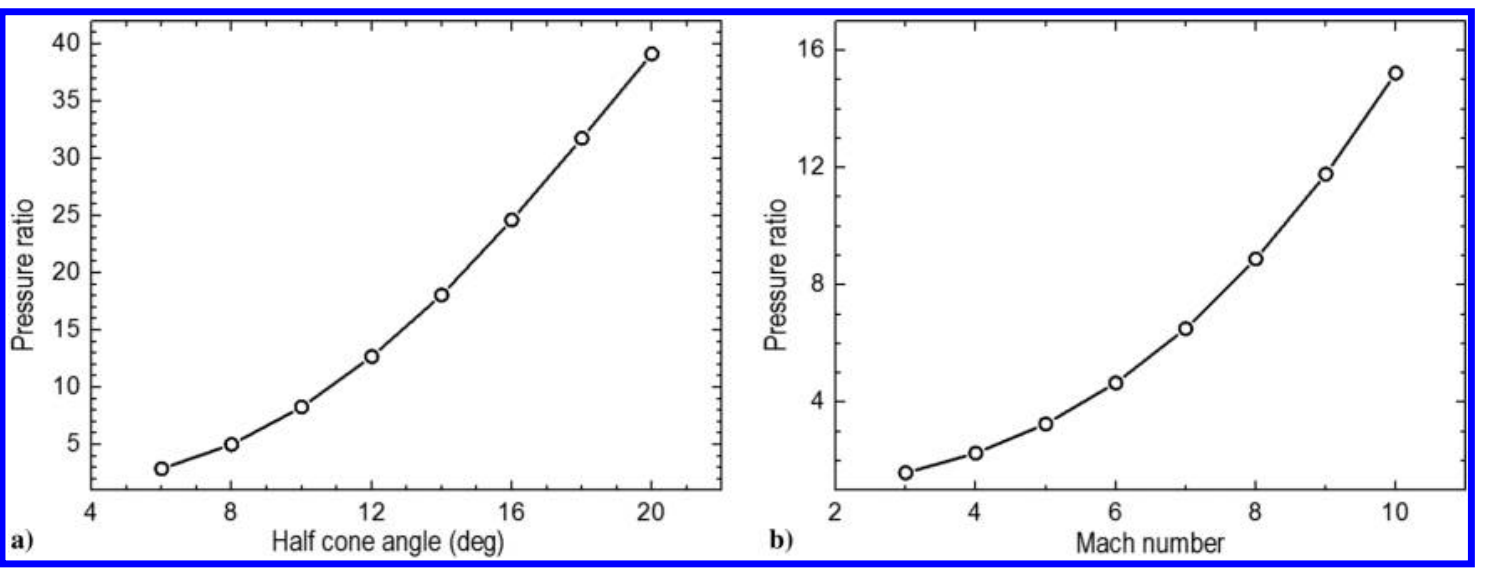

Fig. 5 Variations of $\boldsymbol{\eta}$ with Mach number and wedge angle for cone bodies.

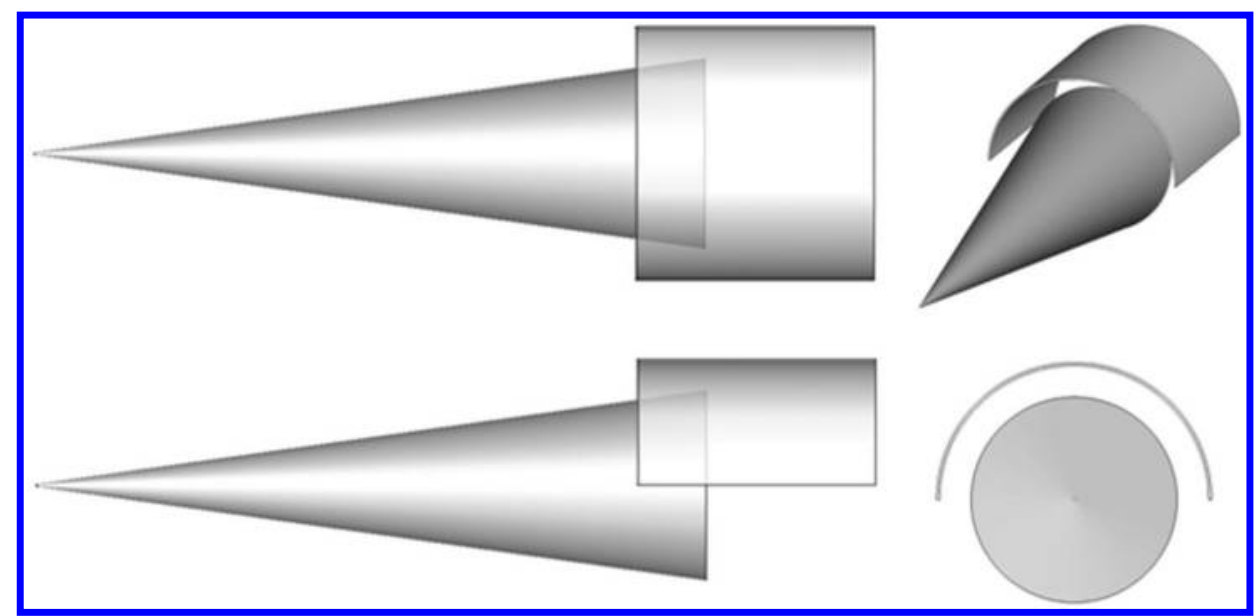

Fig. 6 Conceptual cone-body-HCW configuration.

axisymmetric model. In addition, we can also calculate the aerodynamic forces of the HCW by integrating the pressure distribution on its overall surface while neglecting the threedimensional effect near the wing tip of the HCW. Therefore, the lift and the drag force of this configuration can be calculated using Eq. (2):

$$
\left\{\begin{array}{l}
\boldsymbol{L}=\iint_{S_{B}}\left(p_{B}-p_{\infty}\right) \cdot \mathrm{d} \boldsymbol{s}_{z}+\iint_{S_{H}}\left(p_{H}-p_{\infty}\right) \cdot \mathrm{d} \boldsymbol{s}_{z}, \\
\boldsymbol{D}=\iint_{S_{B}}\left(p_{B}-p_{\infty}\right) \cdot \mathrm{d} \boldsymbol{s}_{x}+\iint_{S_{H}}\left(p_{H}-p_{\infty}\right) \cdot \mathrm{d} \boldsymbol{s}_{x}
\end{array}\right.
$$

where vectors $\boldsymbol{s}_{z}$ and $\boldsymbol{s}_{x}$ are projection areas along the lift and the drag directions; $p_{B}$ and $p_{H}$ are the pressure distributions on the body and on the HCW; and $S_{B}$ and $S_{H}$ are the total surface areas of the body and the HCW. Here, the magnitudes of $p_{B}$ and $p_{H}$ of each element on the surface are computed by a two-dimensional, axisymmetrical CFD analysis, and their directions are determined by corresponding osculating planes on the body and the HCW.

The preceding two-dimensional-based force calculation method may lead to errors because the HCW's wing-tip effect is neglected. To evaluate the amplitude of this error, a pair of contrast tests are made, where a three-dimensional configuration is used as a reference configuration. The thickness of the two-dimensional (2-D) HCW is the same as the three-dimensional (3-D) model. Some main parameters of the configuration are as follows: the length of the cone is $4 \mathrm{~m}$, the half-cone angle is $8 \mathrm{deg}$, the nose blunt diameter of the cone is $15 \mathrm{~mm}$, the length of the HCW is $1.4 \mathrm{~m}$, and the thickness of the $\mathrm{HCW}$ is $15 \mathrm{~mm}$. Freestream conditions are $M a=7, \alpha=0 \mathrm{deg}$, and $H=30 \mathrm{~km}$. Structured grids are used for discretizing the flowfield for both the 2-D and 3-D cases. Total mesh numbers are about 24,000 and 2,778,000 for the 2-D and the 3-D case, respectively. In addition, the grid distributions for the 2-D and the 3-D cases are set as consistent as possible to ensure comparability.
Table 1 lists the computational results in which subscripts 2-D and 3 -D denote the different force calculation methods. Note that the base drag is not included for two cases. The reference area for force coefficient calculation is the base area of the cone body, about $0.985 \mathrm{~m}^{2}$. On one hand, the results show that an HCW can produce a considerable aerodynamic lift. On the other hand, the values of both the lift and the drag calculated by different methods are very close. This means that the wing-tip effect of the HCW can be neglected even with a thickness of $15 \mathrm{~mm}$, and so such a simplified force calculation method can be used in further study.

\section{B. Aerodynamic Performance Versus Volume}

Numerical simulations are carried out for a series of cone-bodyHCW configurations with different half-cone angles using a combination of inviscid CFD analysis and the preceding force calculation method. The thickness of the HCW is zero. In such an idealized configuration, all lift is produced by the $\mathrm{HCW}$, whereas the drag is only produced by the cone body. Thus, the performance of the HCW can be clearly identified. For each case, the leading point of the HCWs is at $x=3.2 \mathrm{~m}$, and the lengths of the cone and the HCW are 4 and $2.8 \mathrm{~m}$, respectively. Cones with different halfcone angles have different volumes. Here, the cone angle varies from 6 to $14 \mathrm{deg}$, and the corresponding volume ranges from 0.74 to $4.166 \mathrm{~m}^{3}$. A grid structure as shown in Fig. $4 \mathrm{a}$ is used for all cases.

Table 1 Force coefficients of the 2-D and the 3-D models

\begin{tabular}{lcccccc}
\hline \hline Parts & $C_{d, 2 D}$ & $C_{d, 3 D}$ & $C_{d, 2 D} / C_{d, 3 D}$ & $C_{l, 2 D}$ & $C_{l, 3 D}$ & $C_{l, 2 D} / C_{l, 3 D}$ \\
\hline Body & 0.0471 & 0.0472 & 0.9977 & 0 & 0 & 0 \\
HCW & 0.0760 & 0.0738 & 1.031 & 0.2739 & 0.2751 & 0.996 \\
Total & 0.1231 & 0.1210 & 1.017 & 0.2739 & 0.2751 & 0.996 \\
\hline \hline
\end{tabular}




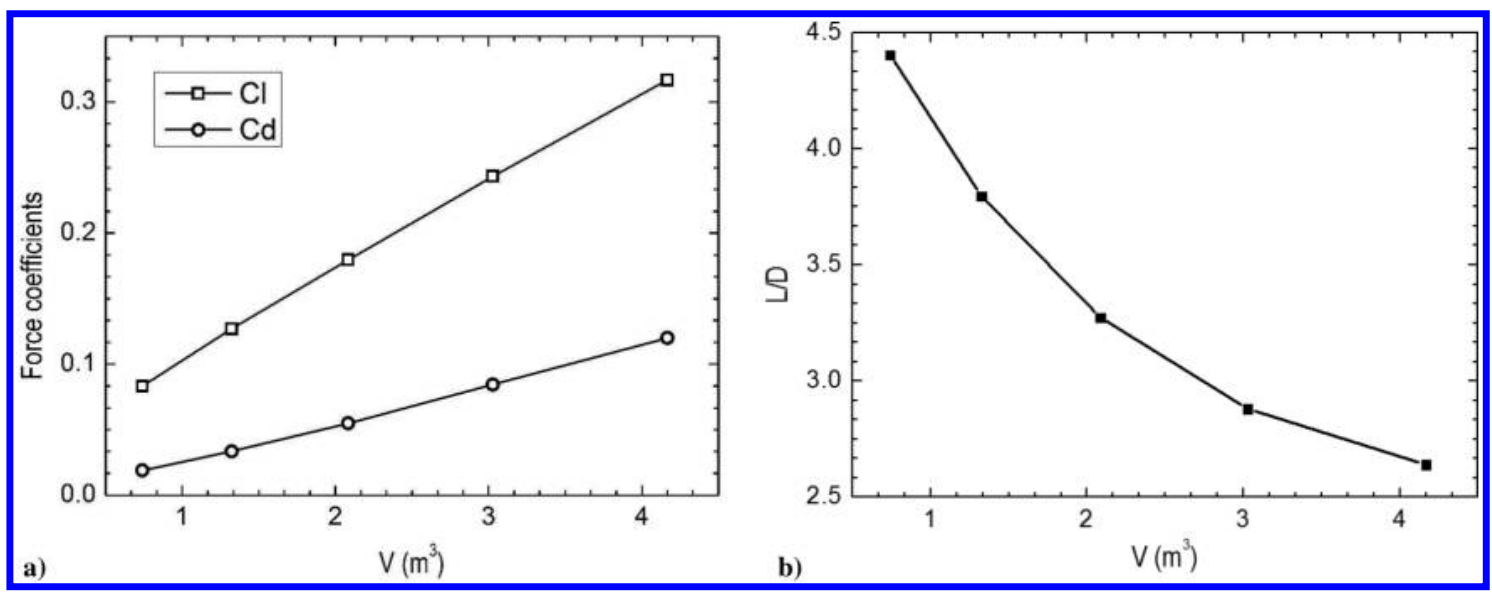

Fig. 7 Aerodynamic coefficients of cone-body-HCW configurations with different volumes.

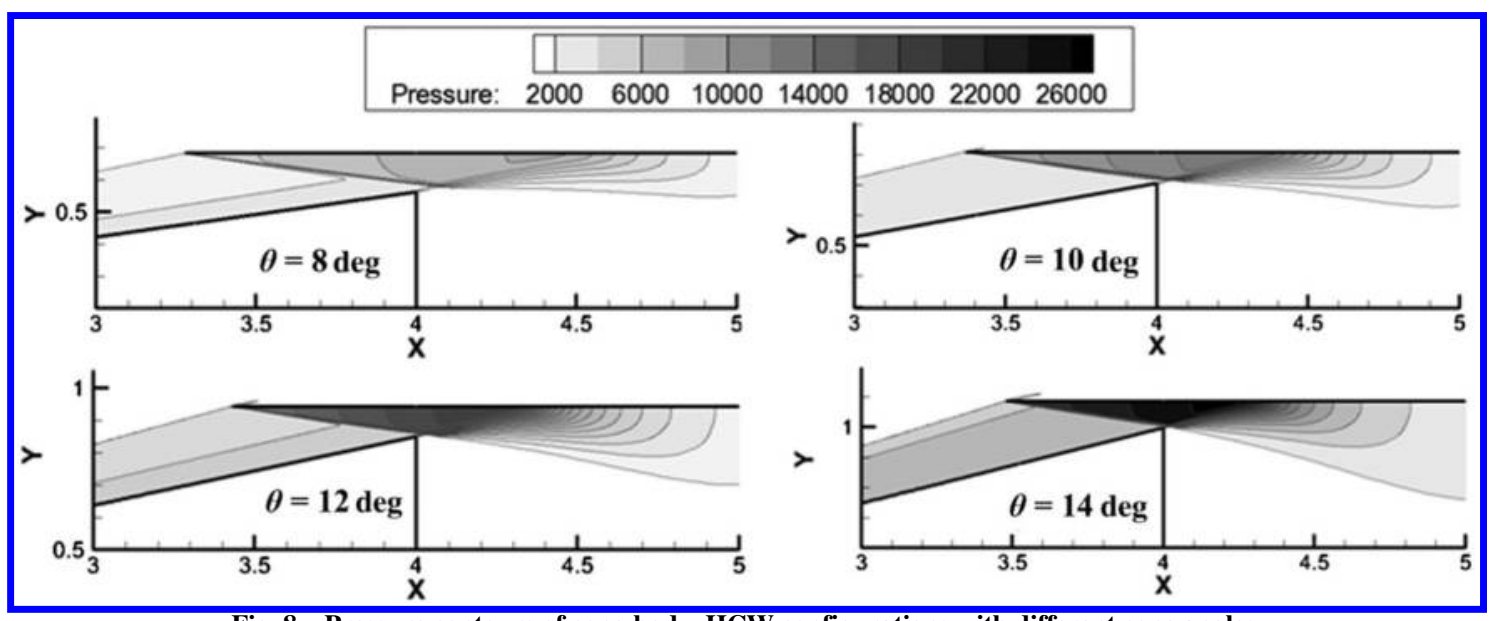

Fig. 8 Pressure contours of cone-body-HCW configurations with different cone angles.

Total mesh number is 527,000 . Freestream conditions are $M a=7$, $\alpha=0 \mathrm{deg}$, and $H=30 \mathrm{~km}$.

Curves of the aerodynamic coefficients versus the volume are plotted in Fig. 7. Pressure contours of configurations with different half-cone angles are shown in Fig. 8 . Note from Fig. 7 that both the lift and the drag coefficients linearly increase with an increase in volume. The reason is that a larger cone angle leads to a stronger shock compression. Accordingly, it results in a larger drag of the cone body. However, at the same time, it also leads to a larger pressure ratio between the lower and the upper surface of the HCW, thereby producing a greater lift. Figure $\underline{8}$ clearly shows this effect. Despite the lift coefficient substantially increasing with the increase in volume, the $L / D$ presents a declining trend from the $L / D$ variation curve shown in Fig. 7.

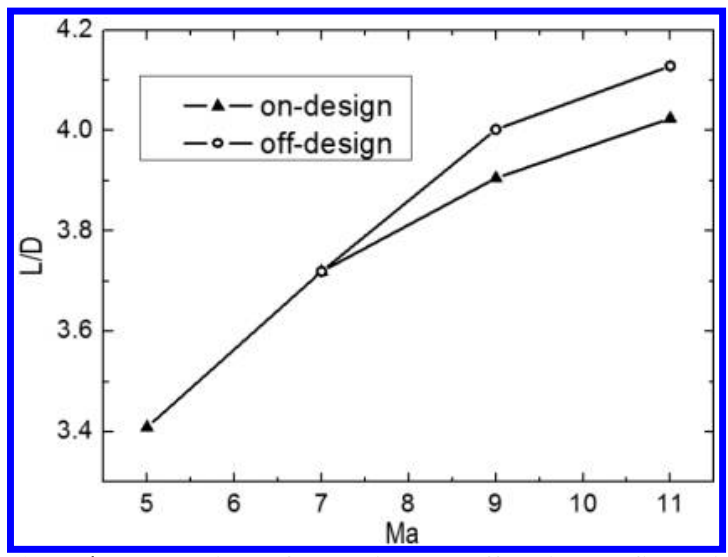

Fig. $9 L / D$ comparison of on-design and off-design configurations.

\section{Aerodynamic Performance Versus Mach Number}

Two categories of numerical test cases were carried out to investigate the relationship between aerodynamic performance and freestream Mach number. A group of "on-design" configurations were designed based on the design rule stated previously, for Mach numbers ranging from 5 to 11 , in which the half-cone angles are $9 \mathrm{deg}$ for all cases. In contrast, the "off-design" configuration used the model at design Mach number 7, and its performance was evaluated at Mach 9 and 11. Because the reflected shock acts on the cone body at Mach 5, the two-dimensional based force calculation method is

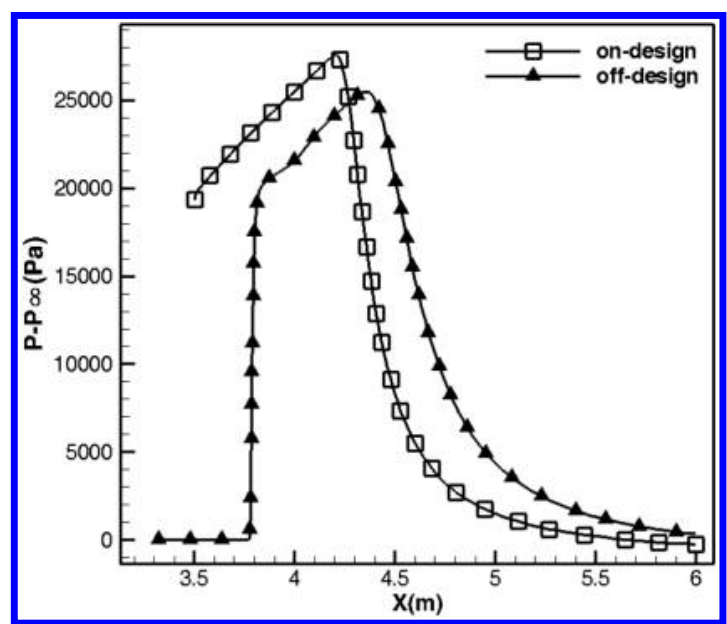

Fig. 10 Pressure coefficient comparison (on the lower surface of the HCW) of on-design and off-design configurations at Mach 11. 


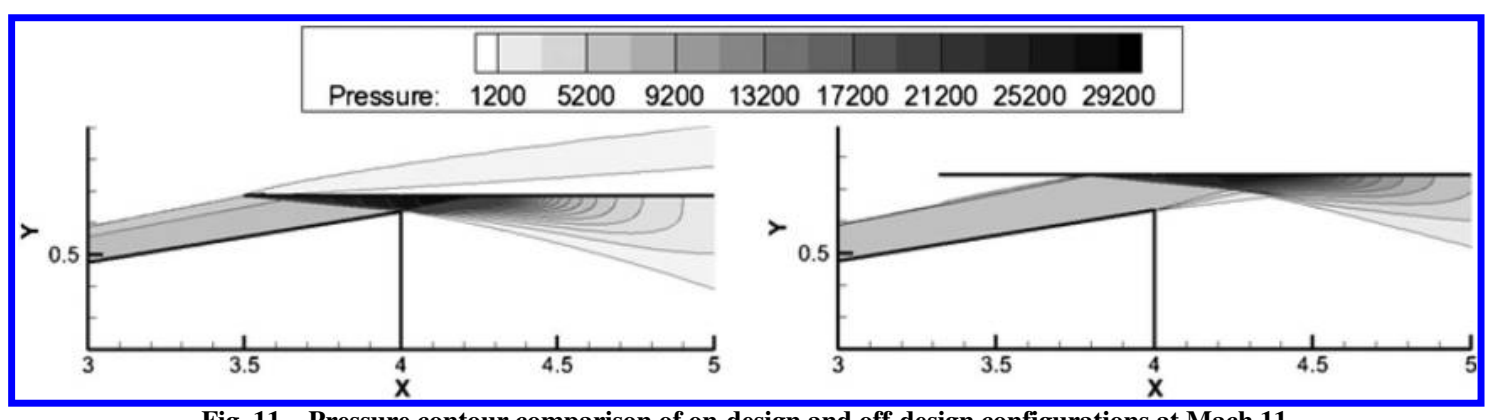

Fig. 11 Pressure contour comparison of on-design and off-design configurations at Mach 11.
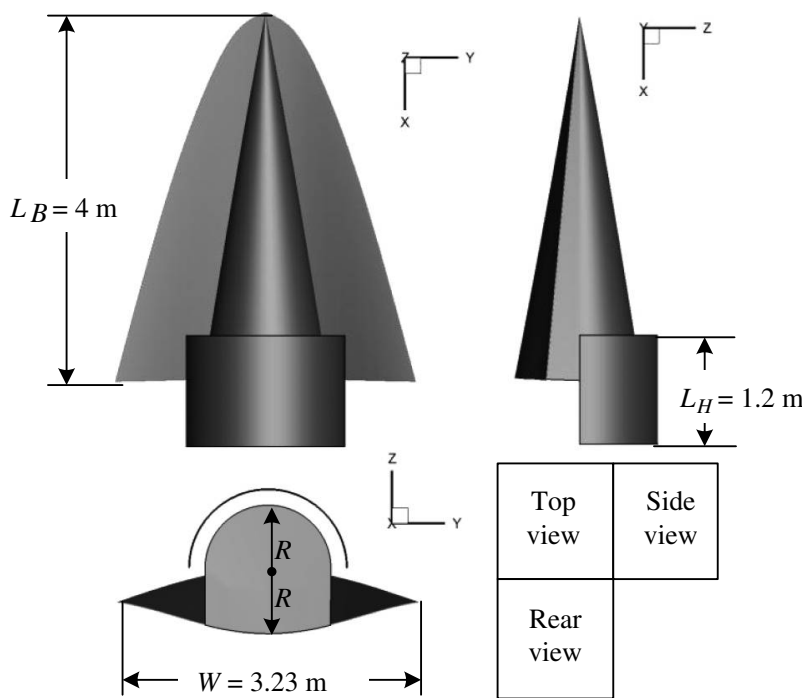

Fig. 12 Three-view of a waverider-HCW combination configuration.

invalid. Therefore, this case is not included in the evaluation of the off-design configuration.

Figure 9 shows the comparison of the $L / D$ values between ondesign and off-design configurations. The curves indicate that the inviscid $L / D$ value increases with the increase in Mach number for either the off-design configuration or on-design configurations. However, it is interesting that the $L / D$ value of the off-design configuration is higher than that of the respective on-design configuration at freestream Mach numbers 9 and 11. To analyze the reasons, pressure distributions on the lower surface of HCWs are plotted in Fig. 10, and the comparison of pressure contours at Mach 11 is shown in Fig. 11. Note from these two figures that the distance between the body and the $\mathrm{HCW}$ of the on-design configuration is smaller than that of the off-design configuration. Thus, the shockexpansion interaction region is quite different for these two configurations. This phenomenon leads to a significant difference in the wall pressure distribution as well as the magnitude of pressure on the lower surface of the HCW. Consequently, the total lift produced by the off-design configuration is higher than that produced by the respective on-design one.

However, it should be noted that we should not draw the conclusion that the off-design configuration is better because the part of the HCW in front of the first shock $S_{1}$ will produce extra skin friction, which was not considered in the present study. The results are only meant to indicate that the performance of the HCW is not sensitive to its position, which is a benefit for its practical application. In addition, the preceding results suggest the existence of an inherently optimal value of the HCW's position. Therefore, a very important problem that needs to be further studied is how to quickly find the optimum for a given HCW configuration.

\section{Waverider-High-Pressure Capturing Wing Combination Configurations}

In the preceding cases, two simplifications of the HCW were adopted for the purpose of clarity in analysis. One is that the thickness of the HCW was assumed to be zero, and the other is that an inviscid Euler model is used. In these cases, the HCW only produces lift and does not produce any wave drag or viscous friction. To evaluate the performance of HCW configurations comprehensively, some more complex configurations are designed. Moreover, a precise NavierStokes equations solver is used.

\section{A. Configurations Description}

Configurations referred to in this section are waverider-HCW combination (WHC) configurations, which comprise two parts: the body and the HCW. The main difference between the WHC and the preceding configurations is the shape of the body. The HCW is a half-barrel shell with limited thickness. The body includes a semicone and a cone-flowfield-derived waverider wing, giving a WHC configuration two lift surfaces: the waverider wing and the HCW. Figure 12 shows a typical WHC configuration, with some important sizes and values mentioned. The thickness of both the waverider wing and the $\mathrm{HCW}$ is $10 \mathrm{~mm}$. Three WHC configurations with different volumes are used as test models, as shown in Fig. 13. Table 2 shows volumetric parameters of three configurations, in which the volumetric efficiency is defined as $\xi=V^{2 / 3} / S_{p}$.

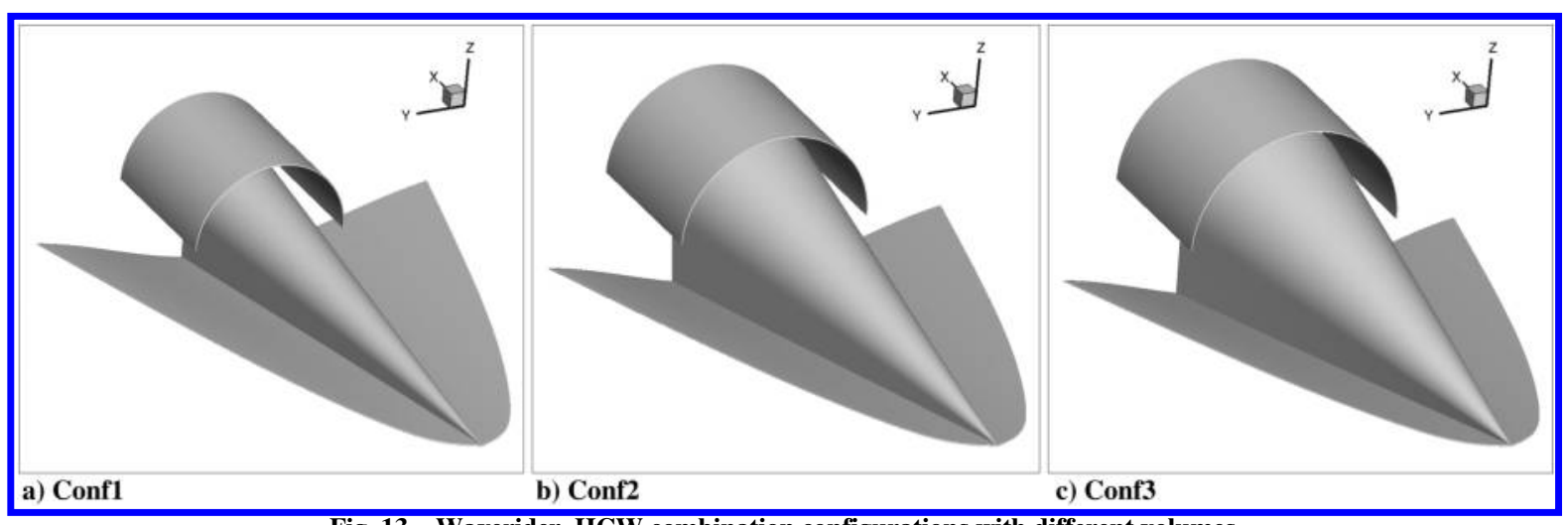

Fig. 13 Waverider-HCW combination configurations with different volumes. 
Table 2 Geometrical parameter comparison of waverider-HCW combination configurations

\begin{tabular}{lccc}
\hline \hline Configuration & $R, \mathrm{~m}$ & $V, \mathrm{~m}^{3}$ & $\xi$ \\
\hline Conf1 & 0.4 & 0.7616 & 0.1030 \\
Conf2 & 0.6 & 1.7136 & 0.1768 \\
Conf3 & 0.7 & 2.3324 & 0.2171 \\
\hline \hline
\end{tabular}

\section{B. Code Validation and Grid Convergence Test}

Cones [34] and HB-2 [35] models are used to validate the reliability of the solver code. The cone with a half-cone angle of $5 \mathrm{deg}$ is $127 \mathrm{~mm}$ long, and the cone with a half-cone of $10 \mathrm{deg}$ is $85.471 \mathrm{~mm}$ long, as shown in Fig. 14a. A freestream Mach number of 9.6 and angle of attack of 0 deg have been used as flow conditions for the cones. The hypervelocity ballistic model, designated HB-2, is a blunted cone-cylinder-flare geometry. The geometric parameters include the radius of the blunted nose $0.3 d$ (where $d$ is the diameter of cylinder), the half-cone angle of $25 \mathrm{deg}$, the cone length of $0.362 \mathrm{~d}$, cylinder of length $2.536 \mathrm{~d}$, and a flare angle of $10 \mathrm{deg}$. The nondimensional total length of the model is $4.9 d$, which is shown in Fig. 14b. A freestream Mach number of 5.1, a Reynolds number of $2.2 \times 10^{6}$ based on $d$, and a different angle of attack have been used as flow conditions. A fully three-dimensional structured grid is used to discretize the computational domain for each of the preceding three configurations. The minimum grid spacing in the normal direction near the body surface is taken to be $1 \times 10^{-5}$ of the length for resolving the thin viscous layers. The value of $y+$ corresponding to this wall grid is less than 5 .

Numerical solutions are calculated by solving the three-dimensional compressible Navier-Stokes equations with the use of a second-order Total Variation Diminishing finite volume scheme for spatial discretization, a second-order implicit time marching scheme, and a realizable $k-\varepsilon$ model that is used in the computations [36]. Table $\underline{3}$ shows the comparison of the cones' drag coefficients between the numerical and experimental results. Figure 15 shows the numerical and experimental results of axial-force coefficient $C_{A}$ and the normal-force coefficient $C_{N}$ for the HB-2 model. The numerical and experimental results are in good agreement, indicating that this numerical technique is reliable for calculating aerodynamic performance.

A fully three-dimensional structured grid is used to discretize the computational domain for each of the preceding three configurations shown in Fig. 13, in which algebraic transfinite interpolation methods with elliptic interior point refinement are used. In addition, an overset grid system is employed for ease of generating grids at the expense of interpolation in the overlapping regions. Thus, the entire domain is decomposed into two subdomains, one around the body and the other around the HCW. All meshes near the wall are refined to capture the boundary layer. Figure 16 shows an example of grid arrangement.

To further verify the accuracy of calculating the WHC configurations, a grid convergence test is carried out by selecting the third configuration (Conf3 in Fig. 13) as an example here.
Table 3 Comparison of numerical results and experimental data for cones

\begin{tabular}{lcc}
\hline \hline$\alpha, \operatorname{deg}$ & $C_{d}$ (CFD) & $C_{d}$ (experiment) \\
\hline 5 & 0.0176 & 0.0170 \\
10 & 0.0575 & 0.0570 \\
\hline \hline
\end{tabular}

Freestream conditions are $M a=7$ and $H=30 \mathrm{~km}$, and the numerical method is the same as the one used in cones and HB-2 models. The results are shown in Fig. 17, in which $\Delta n$ depicts the height of the first layer of the mesh, and $\bar{L}_{B}$ is the length of the body.

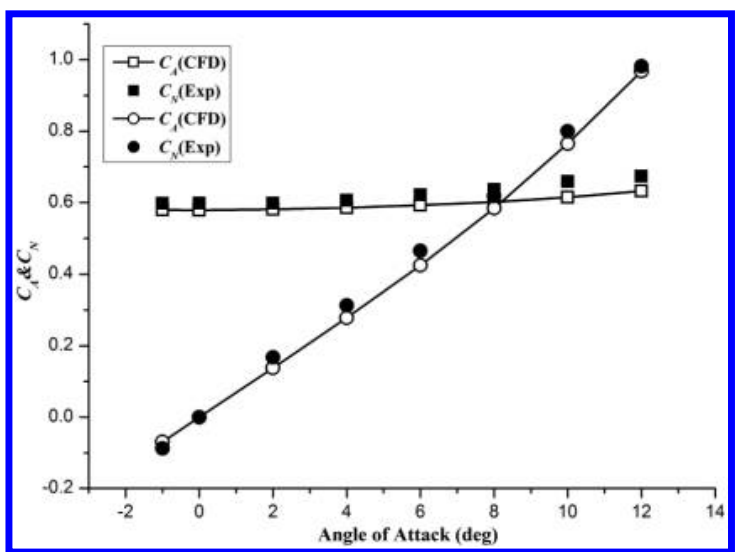

Fig. 15 Comparison of numerical and experimental aerodynamic performance of HB-2 under different angles of attack.

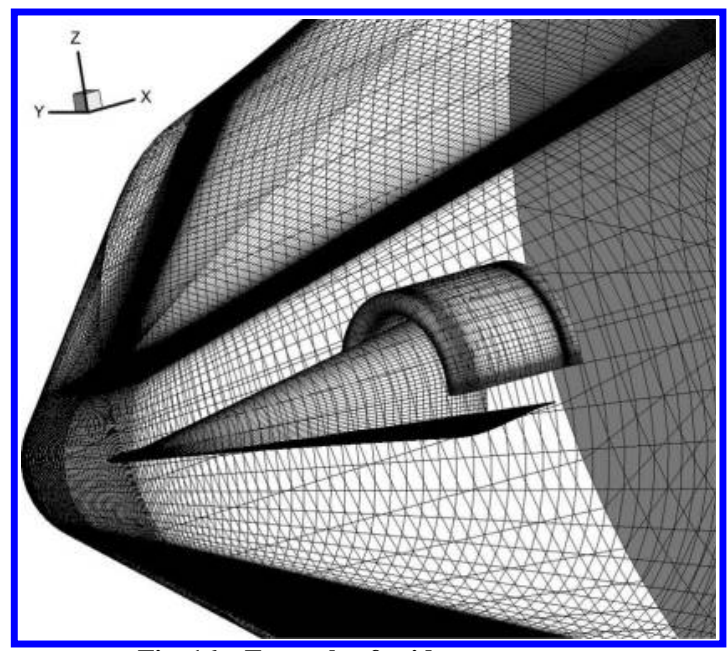

Fig. 16 Example of grid arrangement.

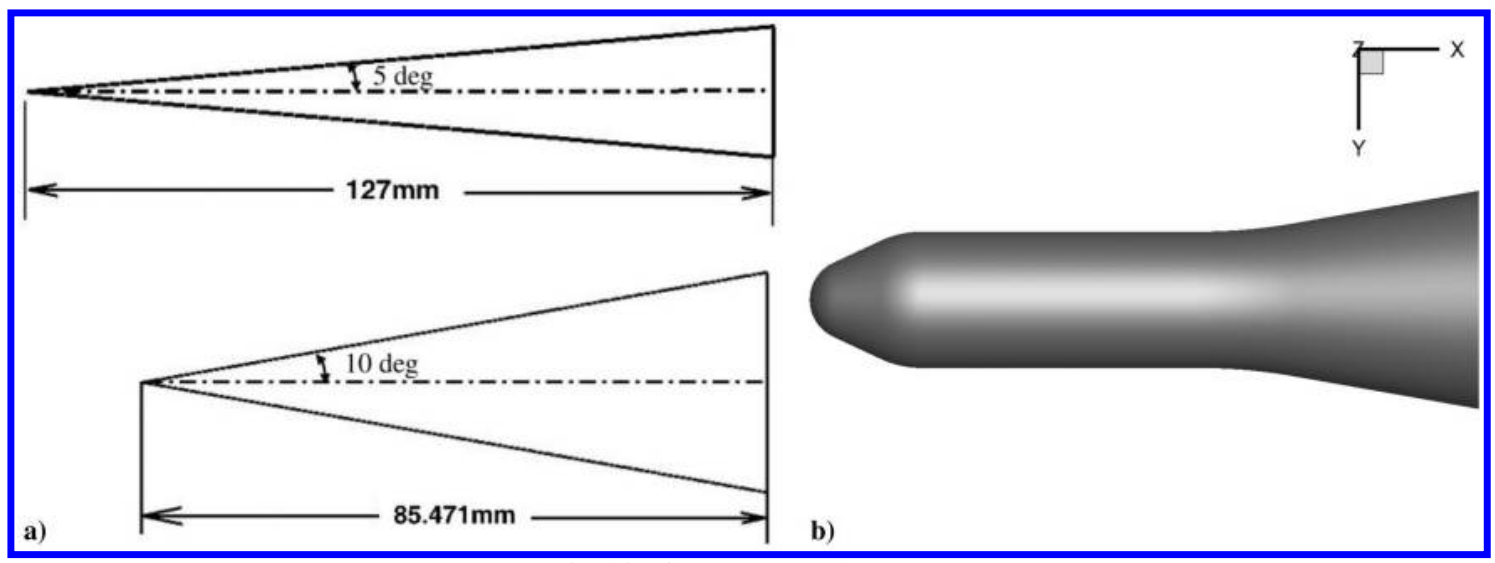

Fig. 14 Cones and HB-2 models. 


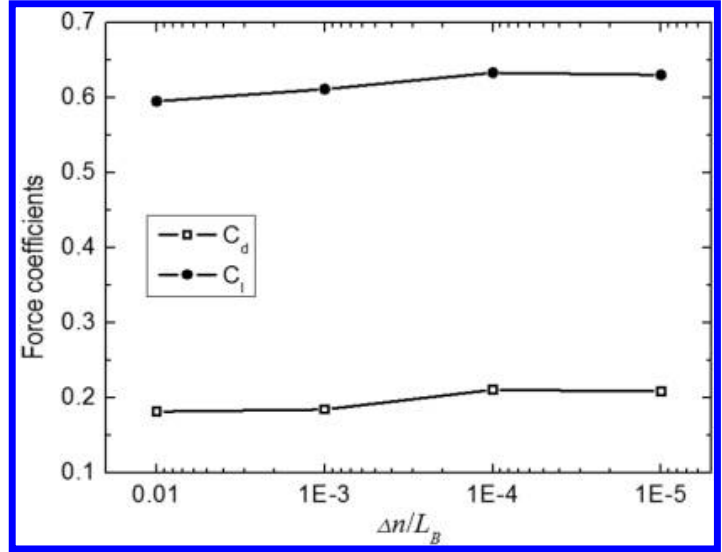

Fig. 17 Results of grid convergence test.

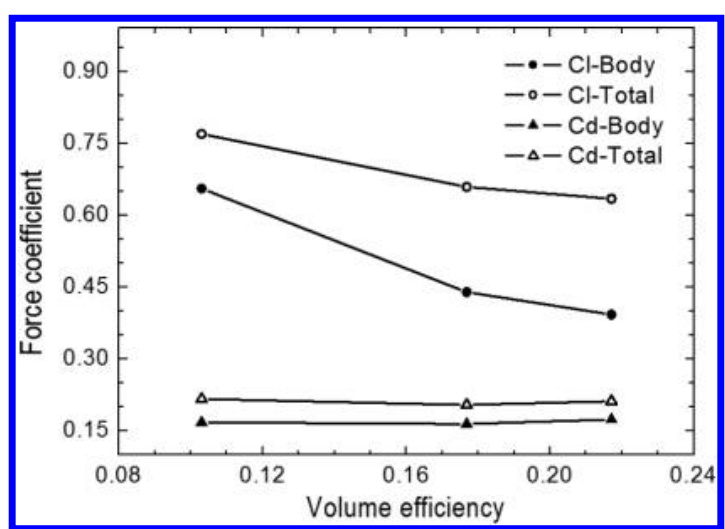

Fig. 18 Lift and drag coefficient comparison of different waveriderHCW combination configurations.

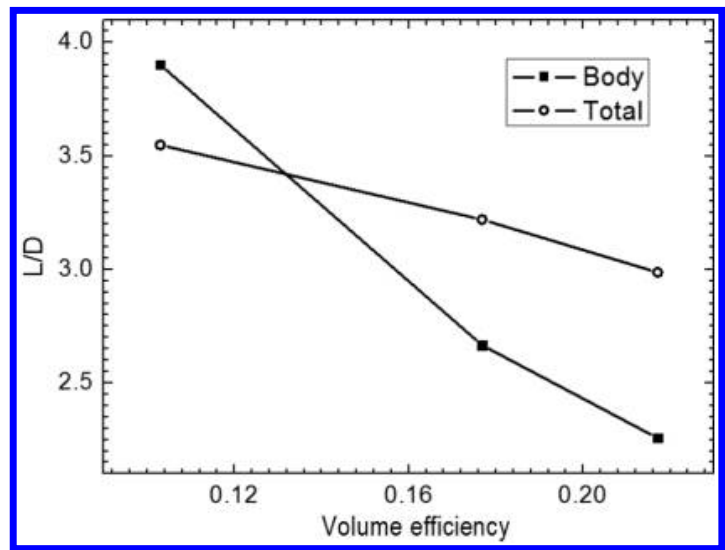

Fig. $19 L / D$ comparison of different waverider-HCW combination configurations.
Note from Fig. 17 that both the lift and the drag coefficients tend to converge with the decrease of $\Delta n$. In the following calculations, $\Delta n$ is taken as $1 \mathrm{E}-5$.

\section{Numerical Results and Analysis}

The lift and drag coefficients' comparison (at $\alpha=0 \mathrm{deg}$ ) of three configurations is shown in Fig. 18. The reference area of each configuration for calculating aerodynamic force coefficients is the base area of the semicone body. Curves labeled "body" include the semicone body and the waverider wing. "Total" refers to the entire WHC configuration. Note from Fig. 18 that the variation of drag coefficients for three configurations is slight, but there is a sensible difference between the body configuration and the total one because the HCW part produces an extra drag. In contrast, the lift improves drastically, benefitting from the HCW of each configuration. Typically for the third configuration $(R=0.7 \mathrm{~m})$, the increasing percentage of the lift is about $61.5 \%$.

The changes of the lift and the drag coefficients naturally lead to the change in $L / D$, as shown in Fig. 19 . The values of $L / D$ for both the body part and the whole WHC configuration decline with the increase in volumetric efficiency. However, the $L / D$ of the body part declines much faster than that of the configuration with an HCW. In the configuration with small volumetric efficiency $(R=0.4 \mathrm{~m})$, the $\mathrm{HCW}$ produces a considerable drag as well as a limited lift because only a weak compression is generated by the semicone body. Thus, the contribution of the $\mathrm{HCW}$ is negative for the $L / D$; in other words, an HCW is not fit for a "thin" body. However, the effectiveness of an HCW gradually emerges with the increase of volumetric efficiency. For the third configuration $(R=0.7 \mathrm{~m}), L / D$ improves about $32 \%$ comparing with the cone-body-waverider configuration. Figure 20 shows pressure contours on the symmetrical plane. This figure further interprets the preceding results.

A series of numerical studies were carried out to examine the aerodynamic performance at different angles of attack as well as Mach numbers by taking the third configuration as an example. Variations of $L / D$ with $\alpha$ are presented in Fig. 21. The results show that the $L / D$ of the whole configuration is higher than that of the body at each angle of attack, but the difference diminishes as $\alpha$ increases. Pressure contour comparisons on the symmetrical plane and the cross-sectional plane $x=3.9 \mathrm{~m}$ at different angles of attack are shown in Fig. 22. Figure 23 shows the HCW's lift and drag percentages of the total. These two figures show that pressure contours at different $\alpha$ present a clear difference. The HCW mainly contributes to generating lift at small or negative angles of attack, and then the key role of producing lift is replaced by the waverider wing with the increasing of $\alpha$. Therefore, the configuration that uses an $\mathrm{HCW}$ registers high $L / D$ values with the varying of angle of attack in a large range.

Curves of aerodynamic lift versus drag for configurations with and without the HCW are shown in Fig. 24. Note from this figure that the curve labeled "total" is on top of the curve labeled "body". This means that a larger lift could be produced by appending an HCW at a given value of the drag; also, the configuration with an HCW can reduce the aerodynamic drag effectively by adjusting $\alpha$ when the lift is fixed as a constraint.

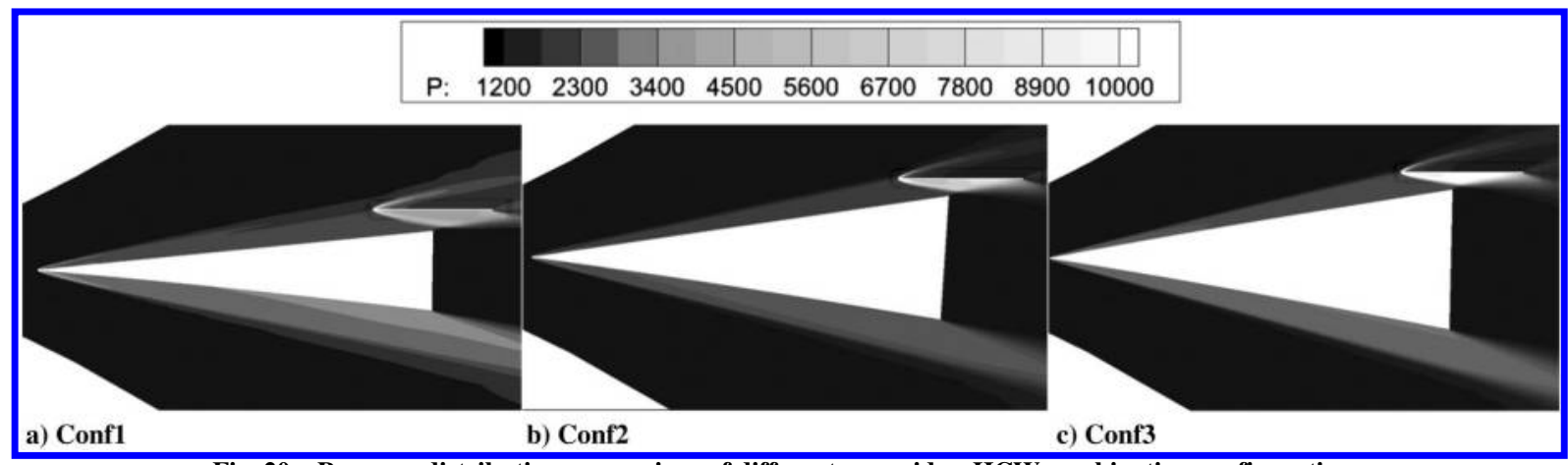

Fig. 20 Pressure distribution comparison of different waverider-HCW combination configurations. 


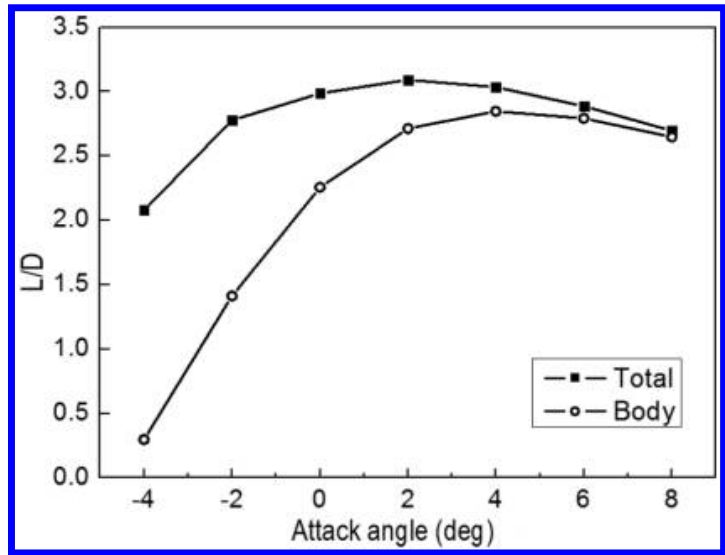

Fig. 21 Variation of $L / D$ with angle of attack.

Lift and drag coefficients' comparison (at $\alpha=0 \mathrm{deg}$ ) of configurations with and without the $\mathrm{HCW}$ at different Mach numbers is shown in Fig. 25. As seen in this figure, both the lift coefficient and the drag coefficient for each configuration decline slowly with the increasing of the Mach number. At the same Mach number, the difference between $C_{l}$ of the total and body is much larger than the difference between $C_{d}$ of the total and

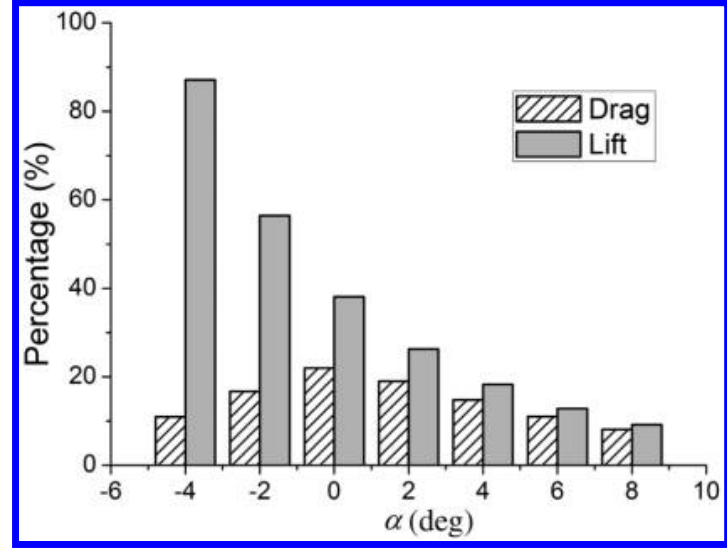

Fig. 23 HCW's lift and drag percentages of the total.

body because of the existence of the HCW. Figure 26 shows the variation of the $L / D$ with the Mach number for two configurations. The result shows that the $L / D$ slightly increases for the body (from 2.18 to 2.28) but apparently increases (from 2.72 to 3.15) for the WHC configuration as Mach number increases, which verifies again that the $\mathrm{HCW}$ is more effective as the Mach number increases.

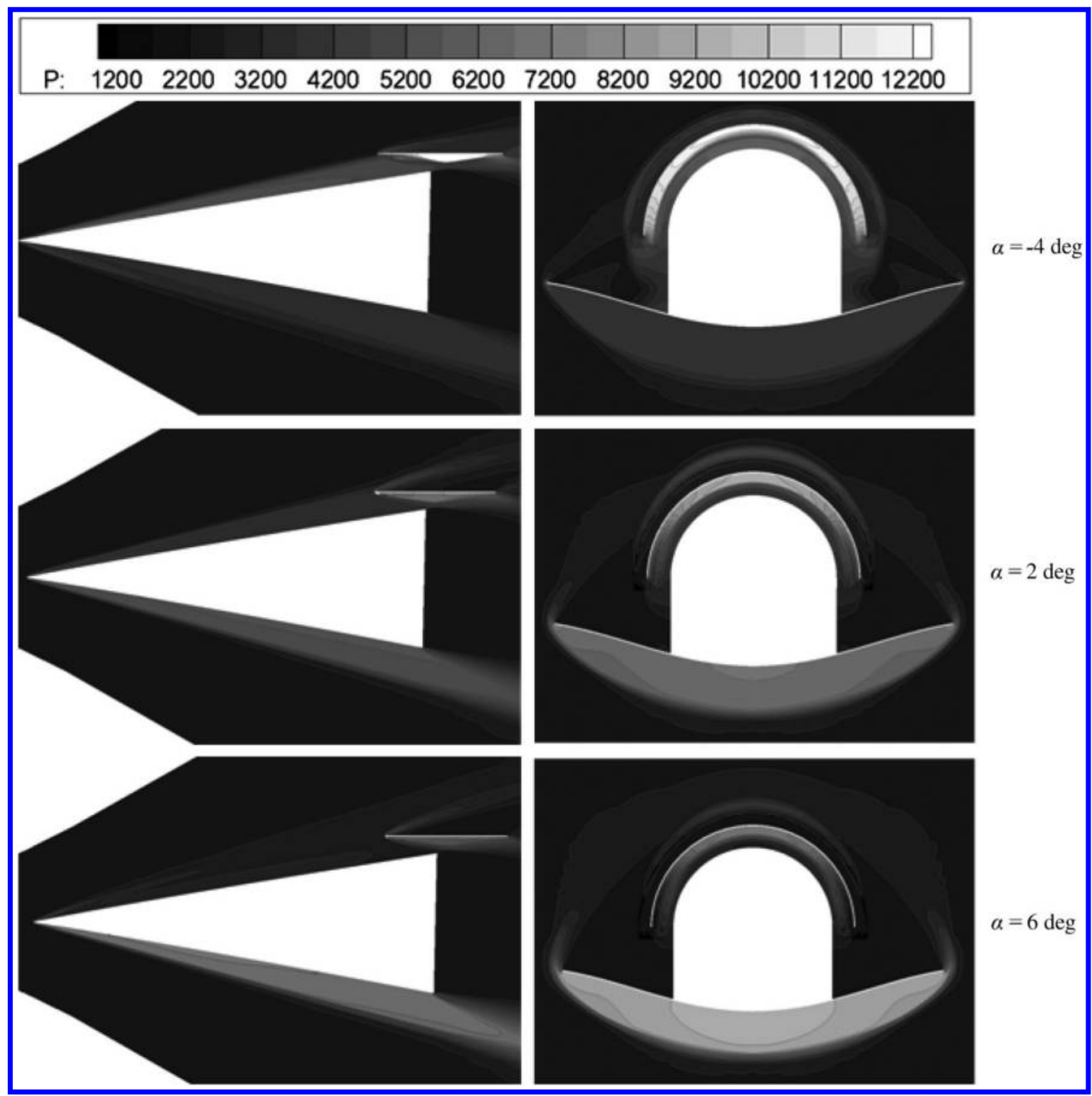

Fig. 22 Pressure contours comparison on the symmetrical plane and the cross-sectional plane $x=3.9 \mathrm{~m}$ at different angles of attack. 


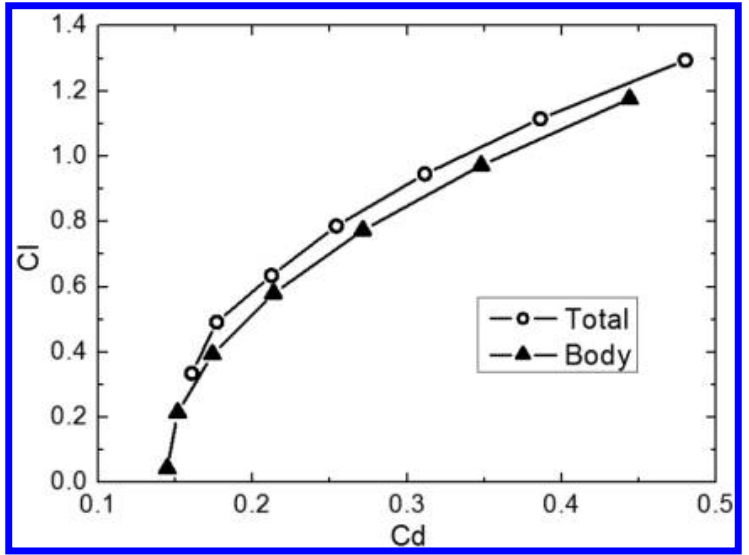

Fig. 24 Aerodynamic lift vs drag for two configurations.

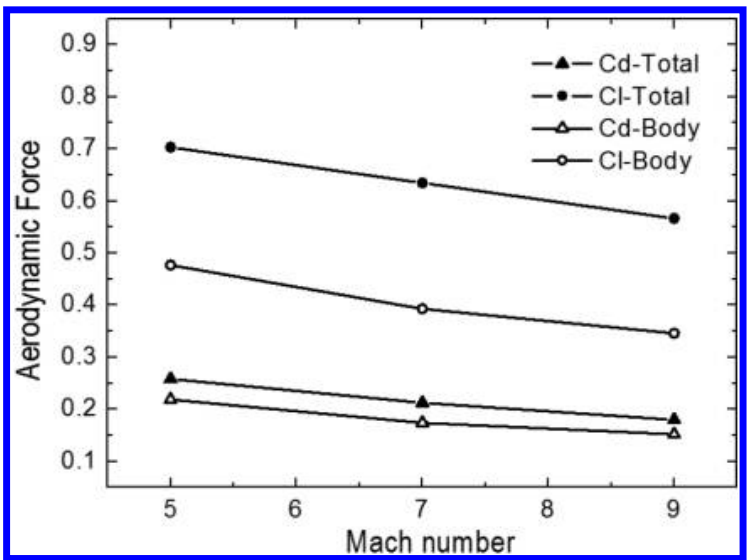

Fig. 25 Lift and drag coefficients vs Mach number for the body and the WHC configurations.

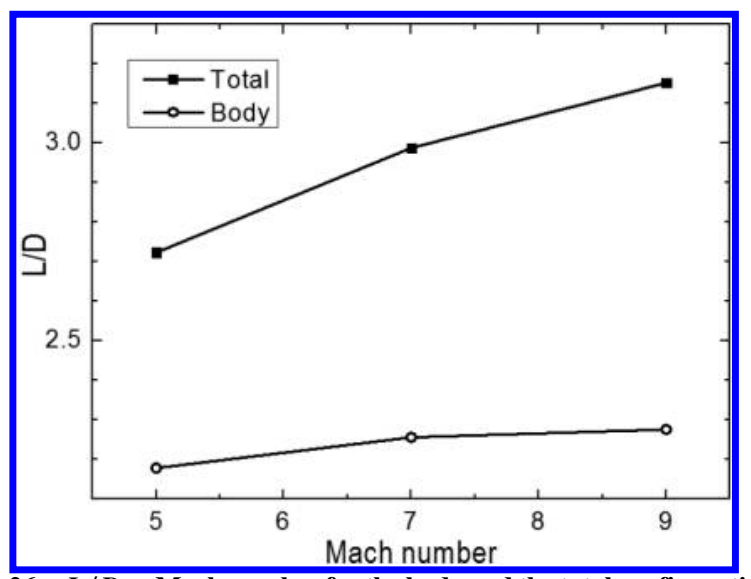

Fig. $26 L / D$ vs Mach number for the body and the total configurations.

Three waverider-HCW combination configurations with different volumes were taken as models to further examine the effect of the $\mathrm{HCW}$ in this section. Present results demonstrate the advantage of HCWs, although these configurations are somewhat conceptual. The loss of the lift for a vehicle with a large volume is effectively compensated by an HCW. Thus, it leads to a considerable improvement of the $L / D$. In addition, a waverider-HCW combination configuration presents a double-wing layout by appending an HCW. Because the main source of aerodynamic lift alternates between the waverider wing and the HCW with the variation of angle of attack, the $L / D$ holds high values as the angle of attack varies in a large range. It should be noted that a $10 \mathrm{~mm}$ thickness of the HCW may be too thin to accommodate adequate structure and thermal protection for a practical application. In the future, an HCW may be designed with nonuniform thickness to deal with this problem.

\section{Conclusions}

A new kind of configuration, which aims to enhance the aerodynamic performance of hypersonic aircraft with large volume requirements, was proposed for potential application in rocketpowered hypersonic cruise vehicles. Configurations were developed as validation cases in accordance with the design philosophy of the high-pressure capturing wing ( $\mathrm{HCW})$. Further, computational fluid dynamics analysis-based aerodynamic performance predictions were made to validate the effectiveness of the HCW. Numerical results clearly demonstrated the advantages of such configurations. The $L / D$ of an aircraft gains considerably as a result of the HCW. However, an HCW is effective only when the body generates strong compression.

For an HCW, the source of the lift is the high-pressure airflow compressed by the body. This is quite different from existing highspeed flight vehicles whose lifts are obtained by compressing freestream airflow directly. Moreover, lift that is produced by the $\mathrm{HCW}$ increases with volume. Thus, the loss of lift due to the upper surface compression could be effectively compensated by appending an $\mathrm{HCW}$

An HCW is a parasitic device that should be combined with a bluff or rounded vehicle body rather than a flat one. The reason is that the strong compression on top of the body can be augmented by appending an HCW. In such cases, the cross-sectional area of the $\mathrm{HCW}$ will be much smaller than that of the body. Thus, the drag generated by the HCW can be treated as relatively small. Consequently, the total drag of the vehicle may only increase slightly compared with the configuration without the HCW. Finally, the weight of the HCW will also be infinitesimal in contrast with both the lift and the gross weight of the entire vehicle because a configuration with a large volume usually carries a large weight. In addition, our results show that the variation in angle of attack has a significant effect on the performance of an HCW. An HCW can only produce very limited lift at a high angle of attack. Fortunately, small angle of attack is always adopted for a high-speed aircraft to reduce the drag, especially at its cruising stage.

There is only a small distance between the body and the HCW, and so the total size of the whole vehicle could be reduced effectively if an $\mathrm{HCW}$ acts on the main lift-generating device. Moreover, a flight vehicle can be designed to be more compact than present-day highspeed aircraft with large wings. Various challenges still exist for such a new concept, such as aerodynamic heating, shock/boundary-layer interaction, shape optimization, stability analysis, etc. In addition, the struts required to attach an $\mathrm{HCW}$ to a body were not considered because all configurations presented in this paper are in the conceptual level. Both the drag and aerothermal impacts produced by HCW attachment struts should be paid more attention to in the future. Other studies are currently investigating these problems.

\section{Acknowledgment}

This research was funded by the National Natural Science Foundation of China under grant numbers 11372324 and 11572333. We also appreciated the referees for their constructive comments.

\section{References}

[1] Joseph, H., James, M., and Richard, M., "The X-51A Scramjet Engine Flight Demonstration Program," 15th AIAA International Space Planes and Hypersonic Systems and Technologies Conference, AIAA Paper 2008-2540, April-May 2008. doi:10.2514/6.2008-2540

[2] Bowcutt, K. G., Kuruvila, G., Grandine, T., and Cramer, E., "Advancements in Multidisciplinary Design Optimization Applied to Hypersonic Vehicles to Achieve Performance Closure," 15th AIAA International Space Planes and Hypersonic Systems and Technologies Conference, AIAA Paper 2008-2591, April-May 2008. doi:10.2514/6.2008-2591

[3] Bowcutt, K. G., Smith, S., Kothari, A., Raghavan, V., Livingston, J., and Tarpley, C., "The Hypersonic Space and Global Transportation System: A Concept for Routine and Affordable Access to Space," 17th AIAA International Space Planes and Hypersonic Systems and Technologies 
Conference, AIAA Paper 2011-2295, April 2011. doi: $10.2514 / 6.2011-2295$

[4] McClinton, C. R., Rausch, V. L., Nguyen, L. T., and Sitz, J. R., "Preliminary X-43 Flight Test Results," Acta Astronautica, Vol. 57, Nos. 2-8, 2005, pp. 266-276. doi:10.1016/j.actaastro.2005.03.060

- [5] Fan, J., "Optimal Speed of Hypersonic Cruise Flight," Theoretical \& Applied Mechanics Letters, Vol. 1, No. 1, 2011, Paper 012004. doi:10.1063/2.1101204

[6] Peckham, D. H., and Crabtree, L. F., "The Range Performance of Hypersonic Aircraft," Aeronautical Research Council Current Papers, Aeronautical Research Council Rept. CP-932, London, 1967.

[7] Nonweiler, T. R. F., "Aerodynamic Problems of Manned Space Vehicles," Journal of the Royal Aeronautical Society, Vol. 63, No. 585, 1959 , pp. 521-528. doi:10.1017/S0368393100071662

[8] Bowcutt, K. G., Anderson, J. D., and Diego, C., "Viscous Optimized Hypersonic Waveriders," 25th AIAA Aerospace Sciences Meeting, AIAA Paper 1987-0272, 1987.

-[9] Goonko, Y. P., Mazhul, I. I., and Markelov, G. N., "Convergent-FlowDerived Waveriders," Journal of Aircraft, Vol. 37, No. 4, 2000, pp. 647-654. doi: $10.2514 / 2.2647$

[10] Mangin, B., Benay, R., Chanetz, B., and Chpoun, A., "Optimization of Viscous Waveriders Derived from Axisymmetric Power-Law Blunt Body Flows," Journal of Spacecraft and Rockets, Vol. 43, No. 5, 2006, pp. 990-998. doi: $10.2514 / 1.20079$

[11] Cui, K., Zhao, D. X., and Yang, G. W., "Waverider Configurations Derived from General Conical Flowfields," Acta Mechanica Sinica, Vol. 23, No. 3, 2007, pp. 247-255. doi:10.1007/s10409-007-0069-2

[12] Ding, F., Liu, J., Shen, C. B., and Huang, W., "Novel Approach for Design of a Waverider Vehicle Generated from Axisymmetric Supersonic Flows Past a Pointed von Karman Ogive," Aerospace Science and Technology, Vol. 42, April-May 2015, pp. 297-308. doi:10.1016/j.ast.2015.01.025

[13] Jones, K. D., and Dougherty, F. C., "Numerical-Simulation of HighSpeed Flows About Wave-Riders with Sharp Leading Edges," Journal of Spacecraft and Rockets, Vol. 29, No. 5, 1992, pp. 661-667. doi: $10.2514 / 3.11507$

[14] Liao, J. R., Isaac, K. M., Miles, J. B., and Tsai, B. J., "Navier-Stokes Simulation for Cone-Derived Waverider," AIAA Journal, Vol. 30, No. 6, 1992, pp. 1521-1528. doi: $10.2514 / 3.11096$

[15] Cockrell, C. E., Jr., Huebner, L. D., and Finley, D. B., "Aerodynamic Performance and Flow-Field Characteristics of Two Waverider-Derived Hypersonic Cruise Configurations," 33rd Aerospace Sciences Meeting and Exhibit, AIAA Paper 1995-0736, 1995. doi:10.2514/6.1995-736

[16] Lin, S.-C., and Shen, M.-C., "Navier-Stokes Simulation of a ConeDerived Waverider with Multidirectional Curvature," AIAA Journal, Vol. 34, No. 8, 1996, pp. 1739-1741. doi: $10.2514 / 3.13298$

[17] Cui, K., and Yang, G. W., "The Effect of Conical Flowfields on the Performance of Waveriders at Mach 6," Chinese Science Bulletin, Vol. 52, No. 1, 2007, pp. 57-64. doi:10.1007/s11434-007-0026-2

[18] Lobbia, M. A., and Suzuki, K., "Experimental Investigation of a Mach 3.5 Waverider Designed Using Computational Fluid Dynamics," AIAA Journal, Vol. 53, No. 6, 2015, 1590-1601. doi:10.2514/1.J053458

[19] Huang, W., Ma, L., Wang, Z. G., Mohamed, P., Derek, B. I., Luo, S. B., and Lei, J., "A Parametric Study on the Aerodynamic Characteristics of a Hypersonic Waverider Vehicle," Acta Astronautica, Vol. 69, Nos. 3-4, 2011, pp. 135-140. doi:10.1016/j.actaastro.2011.02.016
[20] O’Neill, M. K. L., and Lewis, M. J., "Design Tradeoffs on Scramjet Engine Integrated Hypersonic Waverider Vehicles," Journal of Aircraft, Vol. 30, No. 6, 1993, pp. 943-952. doi: $10.2514 / 3.46438$

[21] Takashima, N., and Lewis, M. J., "Optimization of Waverider-Based Hypersonic Cruise Vehicles with Off-Design Considerations," Journal of Aircraft, Vol. 36, No. 1, 1999, pp. 235-245. doi: $10.2514 / 2.2430$

[22] Starkey, R. P., and Lewis, M. J., "Critical Design Issues for Airbreathing Hypersonic Waverider Missiles," Journal of Spacecraft and Rockets, Vol. 38, No. 4, 2001, pp. 510-519. doi: $10.2514 / 2.3734$

[23] O' Brien, T. F., and Lewis, M. J., "Rocket-Based Combined-Cycle Engine Integration on an Osculating Cone Waverider Vehicle," Journal of Aircraft, Vol. 38, No. 6, 2001, pp. 1117-1123. doi: $10.2514 / 2.2880$

[24] Cui, K., Hu, S. C., Li, G. L., Qu, Z. P., and Situ, M., "Conceptual Design and Aerodynamic Evaluation of Hypersonic Airplane with Double Flanking Air Inlets," Science China - Technological Sciences, Vol. 56, No. 8, 2013, pp. 1980-1988. doi:10.1007/s11431-013-5288-0

[25] Liu, J., Ding, F., Huang, W., and Jin, L., "Novel Approach for Designing a Hypersonic Gliding-Cruising Dual Waverider Vehicle," Acta Astronautica, Vol. 102, Sept.-Oct. 2014, pp. 81-88. doi:10.1016/j.actaastro.2014.04.024

[26] Ernst, H. H., and Claus, W., Selected Aerothermodynamic Design Problems of Hypersonic Flight Vehicles, Springer, Berlin, 2009, pp. 189-192.

[27] Marcus, L., and Kojiro, S., "Multidisciplinary Design Optimization of Hypersonic Transport Configurations Using Waveriders," 19th AIAA International Space Planes and Hypersonic Systems and Technologies Conference, AIAA Paper 2014-2359, 2014.

[28] Takashima, N., and Lewis, M. J., "Optimized Mission-Oriented Waverider Vehicles with Base Closure," 34th Aerospace Sciences Meeting and Exhibit, AIAA Paper 1996-0810, Jan. 1996. doi:10.2514/6.1996-810

[29] Strohmeyer, D., Eggers, T., and Haupt, M., "Waverider Aerodynamics and Preliminary Design for Two-Stage-to-Orbit Missions, Part 1," Journal of Spacecraft and Rockets, Vol. 35, No. 4, 1998, pp. 450-458. doi: $10.2514 / 2.3375$

[30] Morris, O., "Aerodynamic Characteristics in Pitch of Several RingWing-Body Configurations at a Mach Number of 2.2," NASA TN D$1272,1962$.

[31] Morris, O., and Mark, R., "Aerodynamic Characteristics of a ParasolWing-Body Combination Utilizing Favorable Lift Interference at Mach Numbers from 3.00 to 4.63," NASA TN D-4855, 1968.

[32] Cui, K., and Yang, G.-W., "Shape Optimization for Hypersonic ArcWing Missiles," Journal of Spacecraft and Rockets, Vol. 47, No. 4, 2010, pp. 694-700. doi: $10.2514 / 1.45882$

[33] Anderson, J. D., Fundamentals of Aerodynamic, 5th ed., McGraw-Hill Higher Education, New York, 2011, pp. 608-648.

[34] Ladson, C. L., and Blackstock, T. A., "Air-Helium Simulation of the Aerodynamic Force Coefficients of Cones at Hypersonic Speeds," NASA TN D-1473, 1962.

[35] Gray, J. D., and Lindsay, E. E., "Force Tests of Standard Hypervelocity Ballistic Models HB-1 and HB-2 at Mach 1.5 to 10," Arnold Engineering Development Center (AEDC) TR-63-137, Arnold Air Force Base, Tennessee, 1963.

[36] Huang, W., Li, S. B., Liu, J., and Wang, Z. G., "Investigation on High Angle of Attack Characteristics of Hypersonic Space Vehicle," Science China Technological Sciences, Vol. 55, No. 5, 2012, pp. 1437 1442.

doi:10.1007/s11431-012-4760-6
T. L. Jackson Associate Editor 